\title{
UK Strategies to achieve the MDGs
}

\author{
Adrian Davis
}

DFID Country Director (China and North-East Asia)

\section{DFID $=$ \\ Development}

\section{UK STRATEGIES TO ACHIEVE THE MDGS}

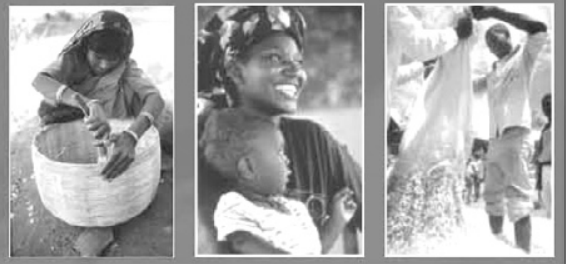




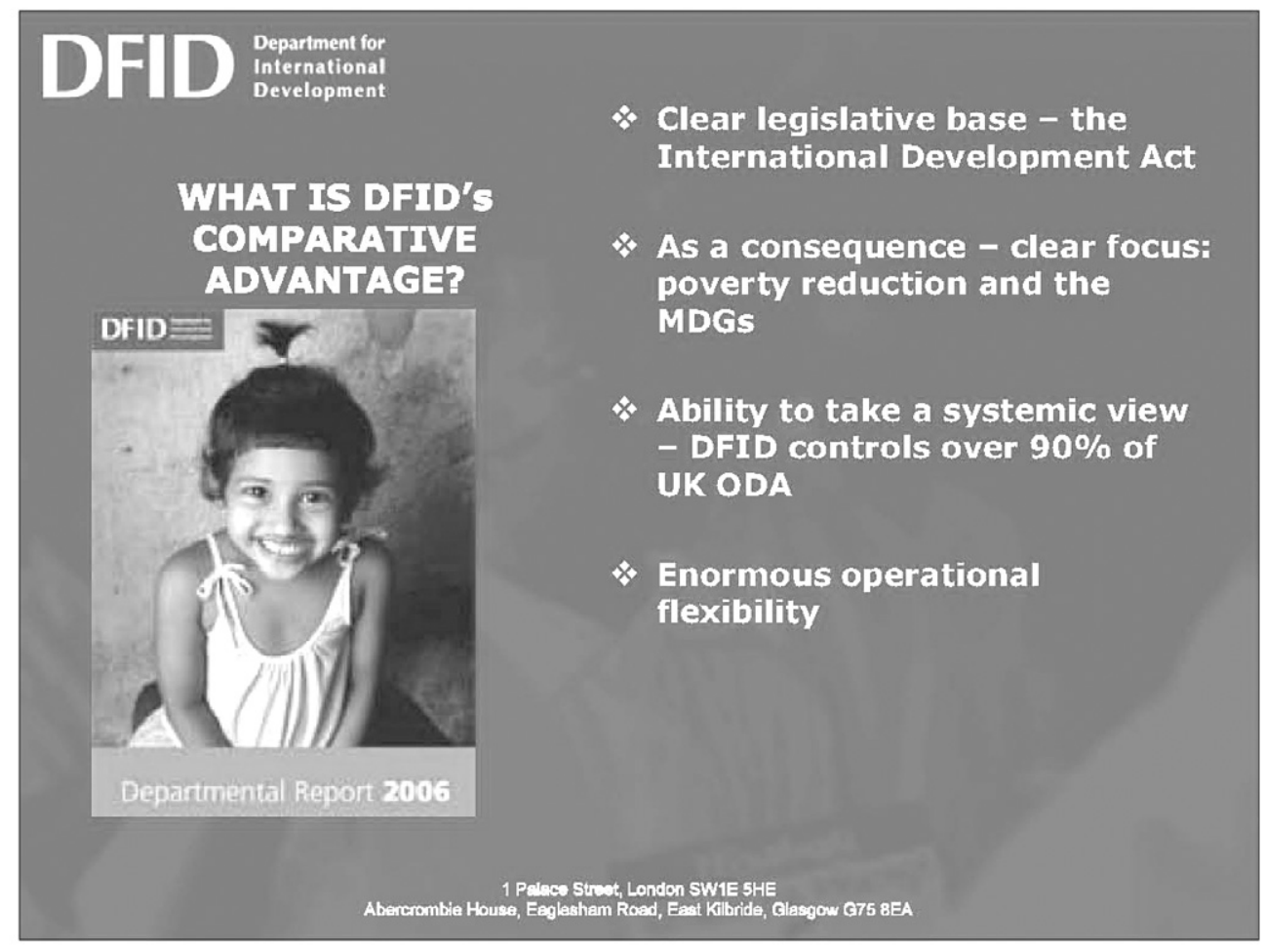

\section{DFID}

\section{WITH PARTNER COUNTRIES}

Develop, support and

promote policy that assists poverty reduction and the achievement of the MDGs

- Country led is a philosophy and a mindset
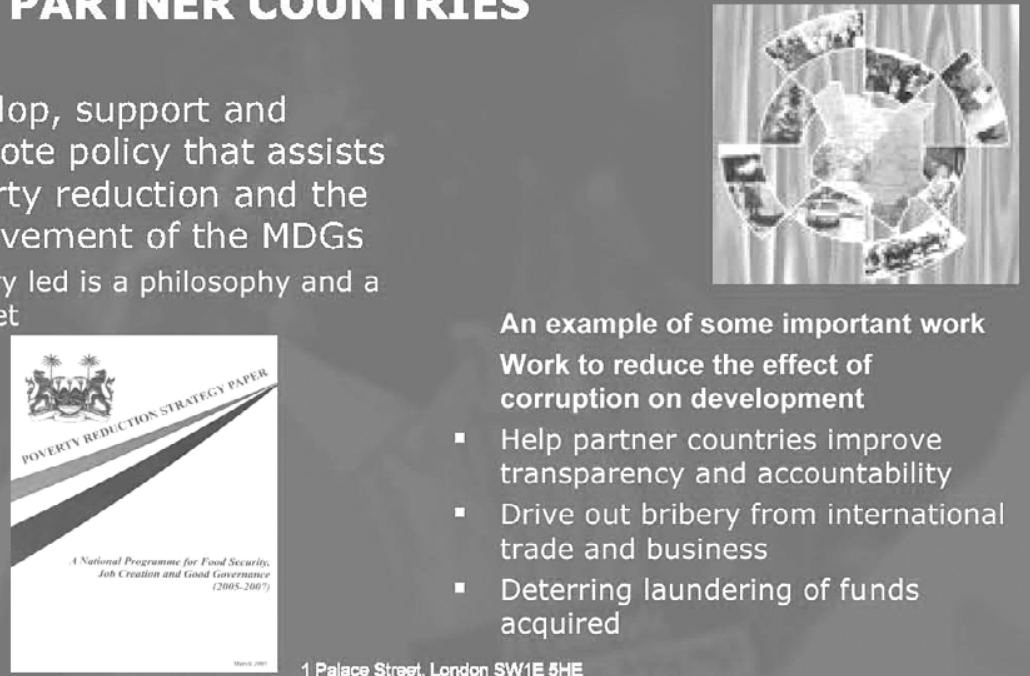

An example of some important work

Work to reduce the effect of corruption on development

- Help partner countries improve transparency and accountability

- Drive out bribery from international trade and business

- Deterring laundering of funds acquired 


\section{DFID Development}

\section{ALLOCATE OUR ATD TO THE RIGHT PLACES}

- $90 \%$ of UK aid goes to low-income countries

- $100 \%$ of UK aid is untied

\section{GIVE IT IN APPROPRIATE WAYS}

- Predicability

- Lack of conditionality

\section{INCREASE THE AMOUNT WE GIVE}

- UK on target to meet $0.7 \%$ pledge by 2013

- Development programme for $2007 / 08$ is $£ 4.3$ billion

- By $2013 / 14$ it will be $£ 10$ billion

\section{DIFFERENT APPROACHES IN DIFFERENT COUNTRIES}

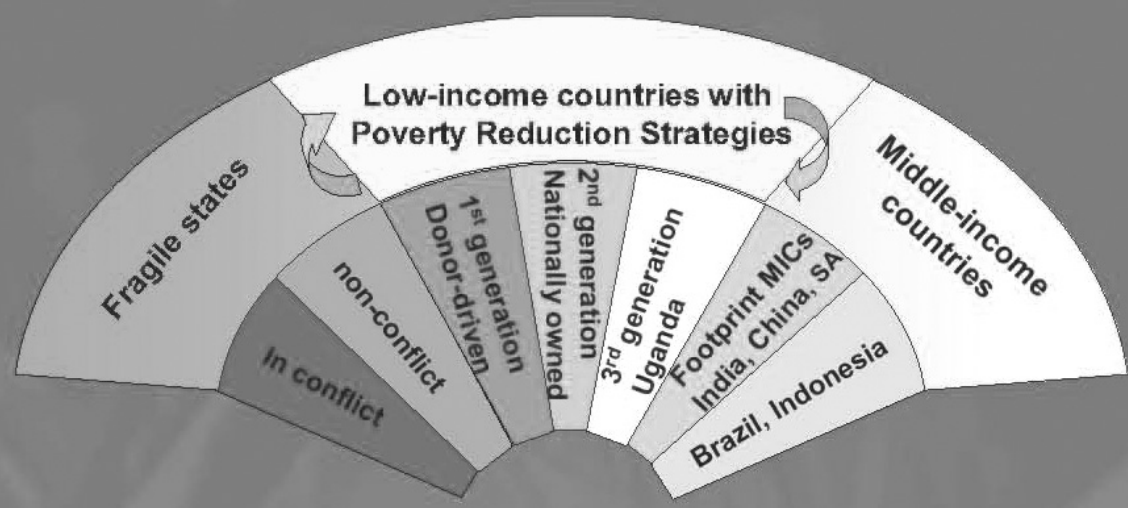




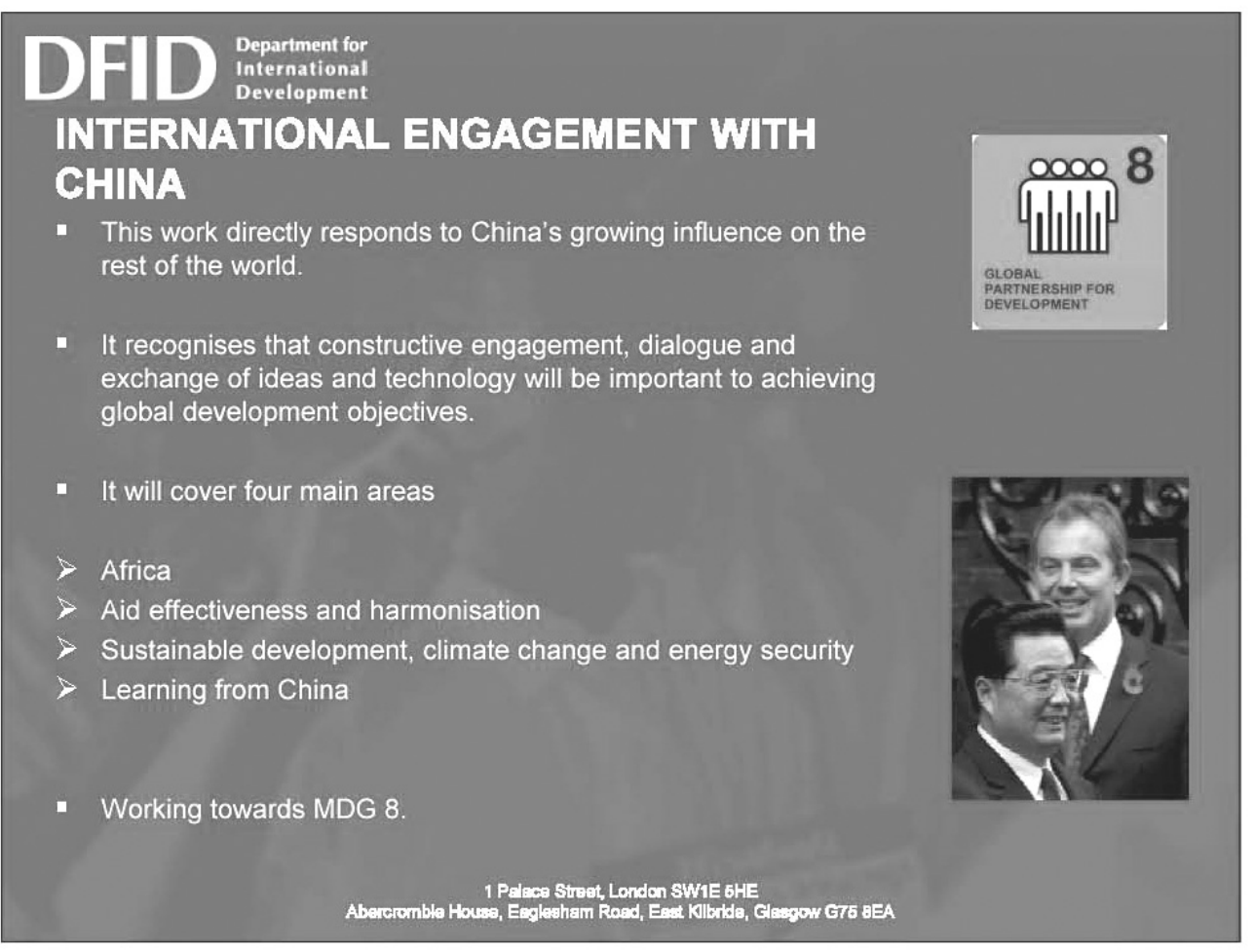

\section{$\mathrm{DFID}=$ Development}

\section{IN THE INTERNATIONAL COMMUNITY}

- Work to promote international agreement on more and better aid

- Make our approach to aid conditionality more consistent and transparent

- Work with international partners to improve the effectiveness of resources devoted to tackling AIDS
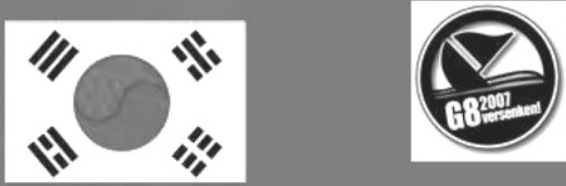

Respond to the global threat of climate change

- Make social protection a higher priority
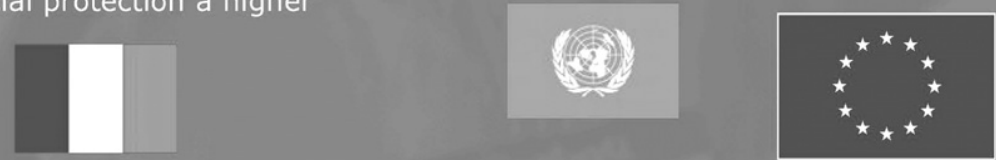


\section{DFID Development}

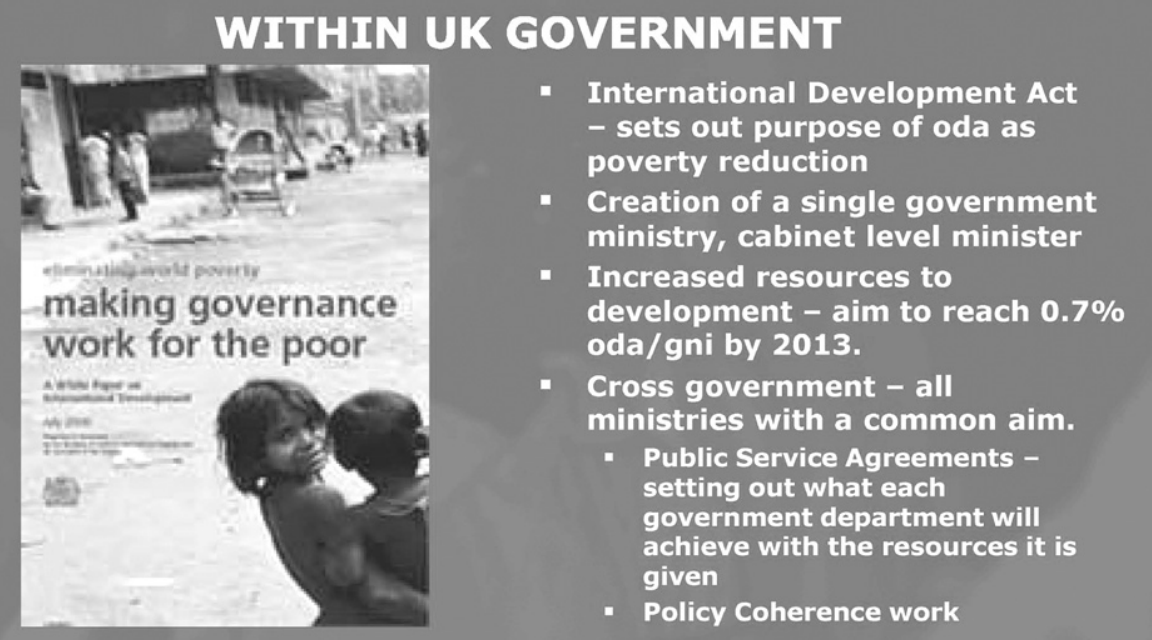

